\title{
Caso 3/2006 - Insuficiência Respiratória Progressiva em Cardiopata de 33 Anos com Acentuado Dismorfismo Somático
}

\author{
Case 3/2006 - Progressive Respiratory Failure in a 33 Year-Old Man with Heart \\ Disease and Remarkable Somatic Dysmorphism
}

Luiz Otávio Savassi Rocha, Beatriz Eugênia Gomes Quirino, Frederico Henrique Corrêa de Melo, Virgínia Hora Rios Leite, Pérsio Godoy, Eugênia Ribeiro Valadares

Hospital das Clínicas da Universidade Federal de Minas Gerais - FMUFMG, Belo Horizonte, MG

Trata-se de um homem (C.J.S.) de 33 anos que, em 19/06/2001, apresentando intensa agitação psicomotora, deu entrada no Serviço de Pronto Atendimento do Hospital das Clínicas da UFMG, com história de um a dois dias de evolução caracterizada por chiado no peito (referido como "crise asmática"), tosse persistente (pouco produtiva, com expectoração mucosa), dispnéia e provável febre. Era etilista contumaz, mas não cultivava o hábito de fumar. Havia menção a tratamento cirúrgico para correção de "hérnia" e biopsia (a céu aberto) para esclarecimento de doença hepática, realizada em 1976 (resultado não disponível).

Ao exame clínico, detectou-se acentuado dismorfismo somático, que incluía: porte atarracado, baixa estatura ( $1 \mathrm{~m} 46 \mathrm{~cm})$; pescoço curto; macrocefalia, com proeminência frontal (perímetro cefálico: $61 \mathrm{~cm}$ ); ponte nasal rebaixada, nariz largo e chato, narinas amplas; orelhas e lábios grosseiros, proeminentes; macrognatia; macroglossia; dentes espaçados, afilados e projetados anteriormente; mãos e pés largos, curtos, com dedos grossos e unhas amplas; tórax deformado, reduzido na porção superior e expandido na inferior; cifoescoliose; genu valgum e pelve reduzida. Identificou-se, também, hipoacusia e deficiência visual, mas, à simples inspeção, não se percebeu turvação corneana. Havia evidente dificuldade respiratória, com esforço predominantemente expiratório. A pressão arterial era $130 \times 70 \mathrm{mmHg}$, a freqüência cardíaca 120 bpm e a freqüência respiratória 38 ipm. Não foram descritas alterações à ausculta cardíaca, ao passo que, à ausculta respiratória, descreveram-se roncos e sibilos disseminados em ambos os hemitórax, além de crepitações, mais evidentes nas bases. 0 fígado, de consistência aumentada, foi palpado a oito centímetros do rebordo costal direito e a dez centímetros do apêndice xifóide.
Diante da suspeita de asma brônquica associada a possível processo infeccioso (sinusite aguda e/ou broncopneumonia), prescreveu-se oxigênio suplementar, micronebulização com fenoterol/brometo de ipratrópio, corticosteróide por via intravenosa, antimicrobiano (amoxicilina) e sintomáticos, sem que se obtivesse melhora significativa.

Hemogramas seriados, realizados em 19/06, 21/06 e $22 / 06$, revelaram expressivo desvio à esquerda (até $16 \%$ de neutrófilos bastonetes) e presença de granulações tóxicas nos neutrófilos, de modo a reforçar a hipótese de infecção bacteriana. Não há menção a estudo radiológico dos seios da face. A radiografia do tórax, realizada logo após a internação, revelou aumento da silhueta cardíaca e configuração "em remo" dos arcos costais, mas não mostrou consolidações (que favorecessem o diagnóstico de processo infeccioso broncopulmonar) nem sinais de congestão/edema pulmonar. Mesmo assim, manteve-se a antibioticoterapia e instituiu-se, também sem sucesso, tratamento para presumível insuficiência cardíaca congestiva, com furosemida, captopril e desacetillanatosídeo C. Solicitou-se ecodopplercardiograma, que foi realizado em condições não muito favoráveis, pois o paciente encontrava-se dispnéico e exibia evidente deformidade torácica. Mesmo assim detectou-se espessamento difuso, leve a moderado, da parede do ventrículo esquerdo (VE); função sistólica biventricular preservada (fração de ejeção do VE: 69\%); espessamento dos folhetos da valva mitral, principalmente do posterior; insuficiência mitral e tricúspide leves; espessamento e hiper-refringência dos folhetos da valva aórtica; insuficiência aórtica moderada (fig. 1); dilatação leve da raiz da aorta; derrame pericárdico leve; hipertensão arterial pulmonar (pressão sistólica em artéria pulmonar estimada em $42 \mathrm{mmHg}$ ). Ao que tudo indica, não se registrou o eletrocardiograma.

Editor da Seção: Alfredo José Mansur (ajmansur@incor.usp.br) Editor Convidado: Luiz Otávio Savassi Rocha

Editores Associados: Desidério Favarato (dclfavarato@incor.usp.br) Vera Demarchi Aiello (anpvera@incor.usp.br)

Correspondência: Luiz Otávio Savassi Rocha • Rua São João Evangelista, 233/301 - 30330-140 - Belo Horizonte, MG E-mail: savassi@estaminas.com.br 


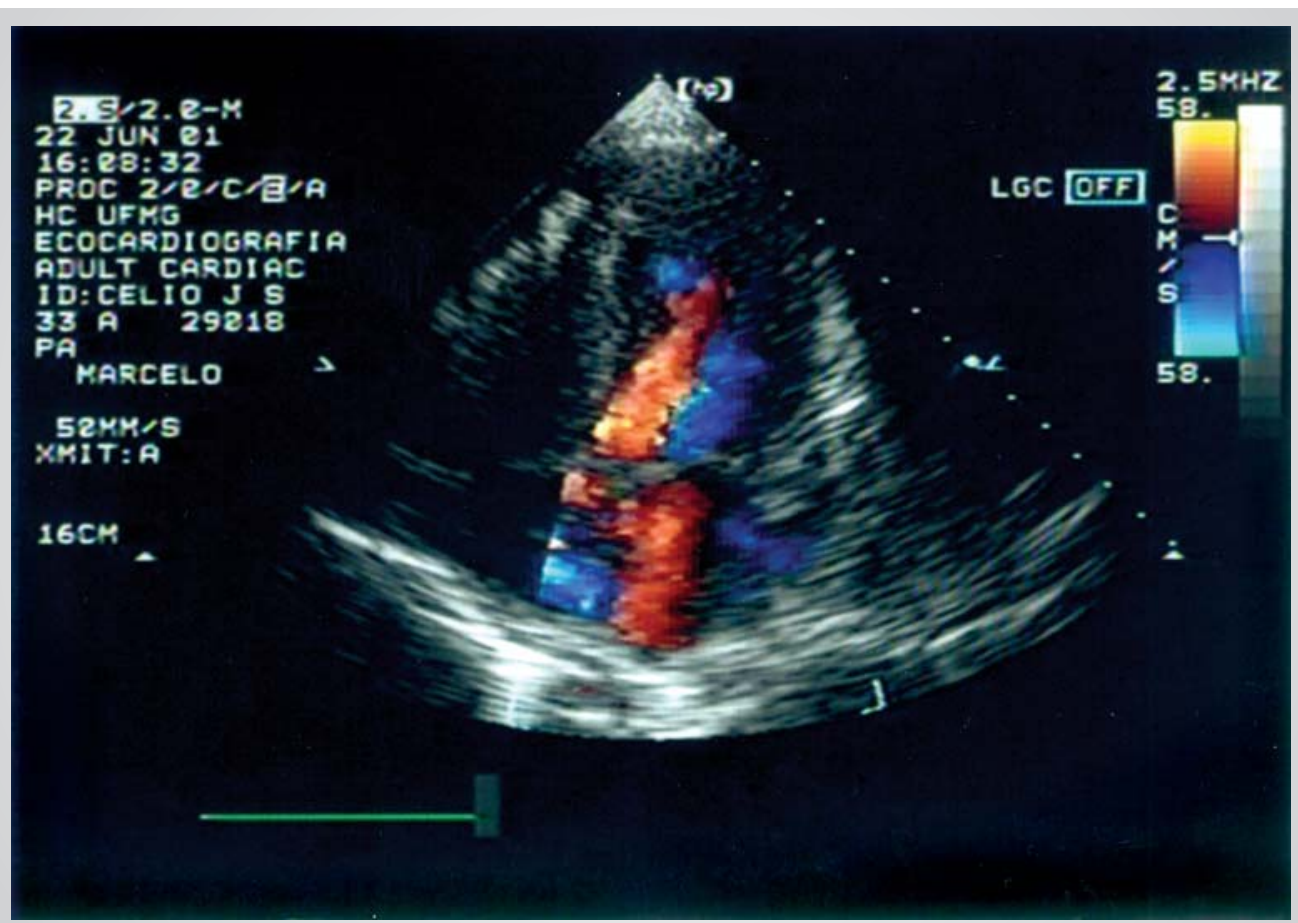

Fig. 1 - Ecodopplercardiograma com mapeamento de fluxo em cores, demonstrando insuficiência aórtica moderada.

A evolução clínica foi catastrófica, marcada por dispnéia intensa e hipoxemia progressiva, e culminou com parada cardiorrespiratória, refratária às manobras de reanimação, prontamente instituídas. Merece registro a grande dificuldade encontrada durante a intubação orotraqueal, somente possível após várias tentativas malsucedidas. 0 óbito foi constatado às 8 h 45min de 23/06/2001.

A avaliação do grupo familiar revelou que dois irmãos (C.A.S. e A.L.S.), ambos etilistas, eram, fisicamente, muito parecidos com o paciente. Um deles (C.A.S.) falecera durante o sono aos 32 anos, com o diagnóstico de glicogenose firmado por punção-biopsia hepática realizada em 1976. O outro (A.L.S.) acabara de completar 26 anos e, além de retardo mental, apresentava baixa estatura, rigidez articular, mãos em garra, hepatomegalia, cicatrizes de herniorrafia inguinal, deficiência visual e hipoacusia.

(Dra. Beatriz Eugênia Gomes Quirino)

\section{Aspectos CLínicos}

No caso ora relatado, as exuberantes manifestações clínicas, aliadas à história familiar, permitiram formular a hipótese de mucopolissacaridose (MPS), em que pese o diagnóstico, presumivelmente equivocado, de glicogenose, formulado mediante punção-biopsia hepática realizada em 1976 no irmão do paciente (C.A.S.) que, anos mais tarde, morreria durante o sono.

Pelo fato de C.J.S. ter falecido quatro dias após a internação hospitalar, não foi possível a confirmação da suspeita clínica, mesmo porque, a julgar exclusivamente pelo fenótipo, as mucopolissacaridoses (MPSs) podem confundir-se com outras doenças lisossômicas como, por exemplo, com algumas mucolipidoses, razão de ser da expressão pseudo-Hurler lipodystrophy, proposta por alguns autores. Ainda mais difícil seria a identificação do tipo de MPS, identificação essa que se baseia na forma da herança, na intensidade do dismorfismo somático, na presença (ou não) de opacificação da córnea, no grau de retardo mental, no perfil de eliminação urinária de glicosaminoglicanos (GAGs) e, sobretudo, na comprovação de deficiência enzimática específica.

Embora a ausculta cardíaca tenha sido considerada normal, admite-se que ela possa ter sido prejudicada pelo fato de o paciente apresentar respiração bastante ruidosa, bem como por sua curta permanência no tumultuado ambiente do Serviço de Pronto Atendimento, de modo a dificultar a percepção de um sopro diastólico suave, aspirativo, de alta freqüência, indicativo de regurgitação aórtica, que, muitas vezes, só é detectado em apnéia pósexpiratória, com o paciente sentado e o tórax inclinado para a frente. Seja como for, a regurgitação aórtica, quantificada como moderada, somente foi identificada pelo ecodopplercardiograma. No que concerne à insuficiência das valvas atrioventriculares, provavelmente não tinha representação à ausculta, por sua pequena magnitude. Quanto à hipertensão pulmonar (pressão sistólica em artéria pulmonar estimada em $42 \mathrm{mmHg}$ ), parece razoável atribuí-la à vasoconstrição induzida pela hipóxia.

A função sistólica biventricular foi considerada normal. O mesmo não se pode dizer da função diastólica do VE, cuja avaliação ecocardiográfica, de grande importância diante da suspeita clínica de doença lisossômica de depósito, ficou prejudicada pela inadequação do registro 
do fluxo diastólico mitral. Importa assinalar, porém, que a avaliação da função diastólica do VE é por demais complexa para basear-se, exclusivamente, nas características do fluxo mitral, mesmo quando seu registro é satisfatório. Em primeiro lugar, pela possível coexistência de fatores de confusão, como regurgitação mitral ou fibrilação atrial; em segundo lugar, pela impossibilidade de se afastar o chamado padrão pseudonormal do fluxo mitral, observado na transição entre os dois tipos básicos de disfunção diastólica: a alteração do relaxamento (tipo I) e o padrão restritivo (tipo II). Para contornar tais dificuldades recomenda-se, sempre que possível, a utilização de outros recursos como a análise do fluxo em veias pulmonares (em especial a amplitude e a duração da onda A reversa), da velocidade de propagação do fluxo da valva mitral até o ápice do VE (com o auxílio do modo$\mathrm{M}$ em cores) e das velocidades durante o relaxamento miocárdico (com o auxílio do Doppler tecidual anular, que independe das condições da pré-carga).

Do ponto de vista do tratamento instituído no Serviço de Pronto Atendimento, chama a atenção a dúvida entre o diagnóstico de obstrução reversível das vias aéreas, razão de ser da prescrição de broncodilatador / corticosteróide, e de insuficiência cardíaca, razão de ser da prescrição de furosemida / captopril / digitálico. Se estivesse disponível, a determinação rápida (15 minutos) dos níveis plasmáticos do peptídeo natriurético cerebral (BNP) ${ }^{1}$ poderia ter contribuído para o diagnóstico diferencial entre dispnéia de origem pulmonar ou cardíaca, mercê do elevado valor preditivo negativo de níveis inferiores a $100 \mathrm{pg} / \mathrm{ml}$, quando se trata de excluir a presença de insuficiência cardíaca sistólica ou diastólica².

A intubação orotraqueal difícil, somente possível após várias tentativas malsucedidas, poderia ser explicada pela associação de pescoço curto, macroglossia, rigidez da articulação temporomandibular e presumível infiltração das vias aéreas, comum nas MPSs. Importa assinalar que tais alterações costumam determinar insuficiência respiratória progressiva e favorecer o surgimento de apnéia obstrutiva do sono (possível causa mortis do irmão do paciente que, aos 32 anos, faleceu enquanto dormia).

Hipóteses diagnósticas: MPS, com acometimento cardíaco. Insuficiência valvar aórtica. Obstrução das vias aéreas superiores. Provável processo infeccioso broncopulmonar. Insuficiência respiratória (causa imediata do óbito).

(Dr. Luiz Otávio Savassi Rocha)

\section{NeCROPSIA}

À necropsia observaram-se depósitos sistematizados, ora focais, ora mais difusos, de substância amorfa ou finamente granular, fracamente corada, não raro conferindo aspecto espumoso às células ("células claras" ou "células gargúlicas"). Tais depósitos foram observados em macrófagos, fibroblastos, células endoteliais e células musculares lisas, bem como na íntima e adventícia vasculares.
O exame do coração, que pesou 400 g, revelou espessamento irregular das valvas semilunares (máxime da aórtica), das valvas atrioventriculares e do endocárdio parietal, com tendência à formação de nódulos. À microscopia, tais alterações eram representadas por tecido conjuntivo, hialinizado em grau variável, encerrando substância amorfa fina, às vezes de aspecto granular, entre as fibrilas e em localização perivascular, abrigando, de permeio, numerosas células claras. Chamava a atenção a presença de dilatação sacular (aneurisma) apical, de 1,0 cm de diâmetro, decorrente da insinuação do endocárdio entre os cornos que formam o vórtex do VE (pertuito, após fixação, de $2,3 \mathrm{~cm}$ de comprimento e 0,2 cm de largura) (fig. 2). Na parede do aneurisma, constituída pelo endocárdio espessado e pelo pericárdio, não se identificavam fibras miocárdicas. Havia aumento da espessura da parede livre do $\operatorname{VE}(2,3 \mathrm{~cm})$ e do septo interventricular, conseqüente, em especial, à infiltração por GAGs, ora mais difusa, ora sob a forma de depósitos densos, em geral subendocárdicos, com grande concentração de células claras. O processo foi observado, de forma conspícua, na região contígua à dilatação sacular apical. Havia hipertrofia de grupos de fibras miocárdicas que, às vezes, exibiam vacuolização perinuclear;

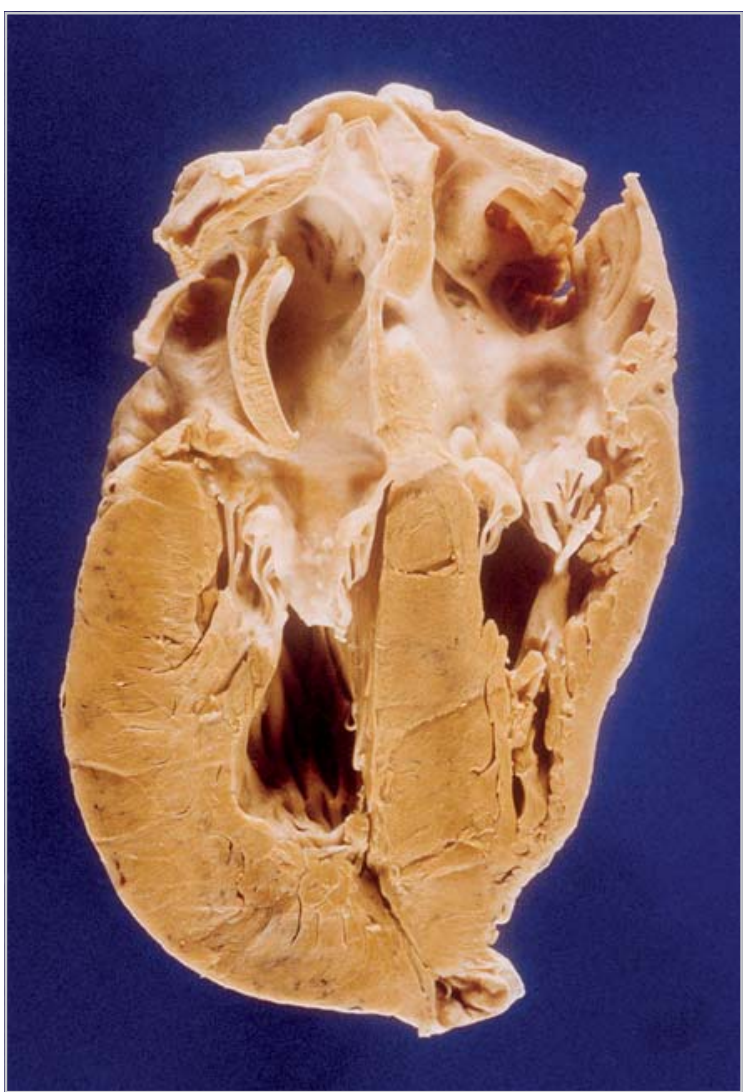

Fig. 2 - Aspecto macroscópico do coração (corte com exposição das quatro câmaras, visão posterior). Chama a atenção o espessamento das valvas atrioventriculares e do endocárdio parietal, bem como a presença de dilatação sacular apical constituída pela insinuação do endocárdio entre os cornos que formam o vórtex do VE. 
ademais, distinguiam-se focos de miocitólise e grupos de cardiomiócitos hipotróficos, com sinais de degeneração miofibrilar. O conjuntivo intra e extrafascicular mostravase alargado, a ponto de promover desorganização dos feixes musculares, especialmente em localização subendocárdica. As coronárias eram rígidas e tortuosas, com redução, não raro acentuada, da luz, decorrente do acúmulo de células claras e de neoformação conjuntiva subintimal e adventicial; diversas pequenas artérias intramiocárdicas também exibiam luzes muito reduzidas (fig. 3). Havia, ainda, acometimento dos gânglios e nervos cardíacos (fig. 3-B), ao passo que o sistema de condução, possivelmente acometido, não foi estudado de forma detalhada.

A laringe mostrava-se infiltrada e a traquéia deformada, enrijecida, com infiltração da parede (em especial da anterior), perda da curvatura normal e acentuada redução da luz (fig. 4); identificavam-se condrócitos agrupados e baloniformes, bem como alterações da matriz cartilaginosa e do colágeno peritraqueal. $\mathrm{O}$ acometimento da traquéia era, em maior ou menor grau, compartilhado pelos brônquios.

O fígado estava aumentado de volume e de peso (1.730 g). Os hepatócitos e as células de Kupffer encontravamse tumefeitos, com citoplasma vacuolado, fracamente positivo à coloração pelo PAS (com diastase) e negativo à pesquisa de lípides (material corado pelo Sudan). Havia ainda esteatose macrovacuolar focal e discreto alargamento fibroso dos espaços porta. A microscopia eletrônica de transmissão revelou, no citoplasma dos hepatócitos e das células de Kupffer, vacúolos revestidos por membrana, contendo material granular de moderada eletrondensidade (aspecto compatível com depósito de GAGs) (fig. 5).

O encéfalo exibia diminutas cavitações $(1,0 \mathrm{~mm}$ de diâmetro, em média), distribuídas difusamente na substância branca, identificando-se, em situação perivascular, numerosos macrófagos espumosos fracamente corados. Havia dilatação acentuada dos ventrículos e do aqueduto cerebral.

Detectou-se, ainda, pancreatite crônica fibrosante, achado compatível com a história de etilismo crônico.

Atribuiu-se o óbito à insuficiência respiratória causada pela obstrução das vias aéreas associada a processo broncopneumônico bilateral, em grandes focos confluentes (peso combinado dos pulmões: $1.617 \mathrm{~g}$ ).

Diagnósticos anatomopatológicos: MPS, com expressivo acometimento cardíaco e obstrução das vias aéreas. Broncopneumonia.

(Dr. Frederico Henrique Corrêa de Melo, Dra. Virgínia Hora Rios Leite, Dr. Pérsio Godoy)

\section{ComentÁRIOS}

Incluídos entre os erros inatos do metabolismo, as MPSs constituem, pelo pleomorfismo das manifestações clínicas, um grupo heterogêneo de afecções que têm em comum o depósito intracelular e a excreção urinária de GAGs, decorrentes da deficiência de enzimas lisossômicas

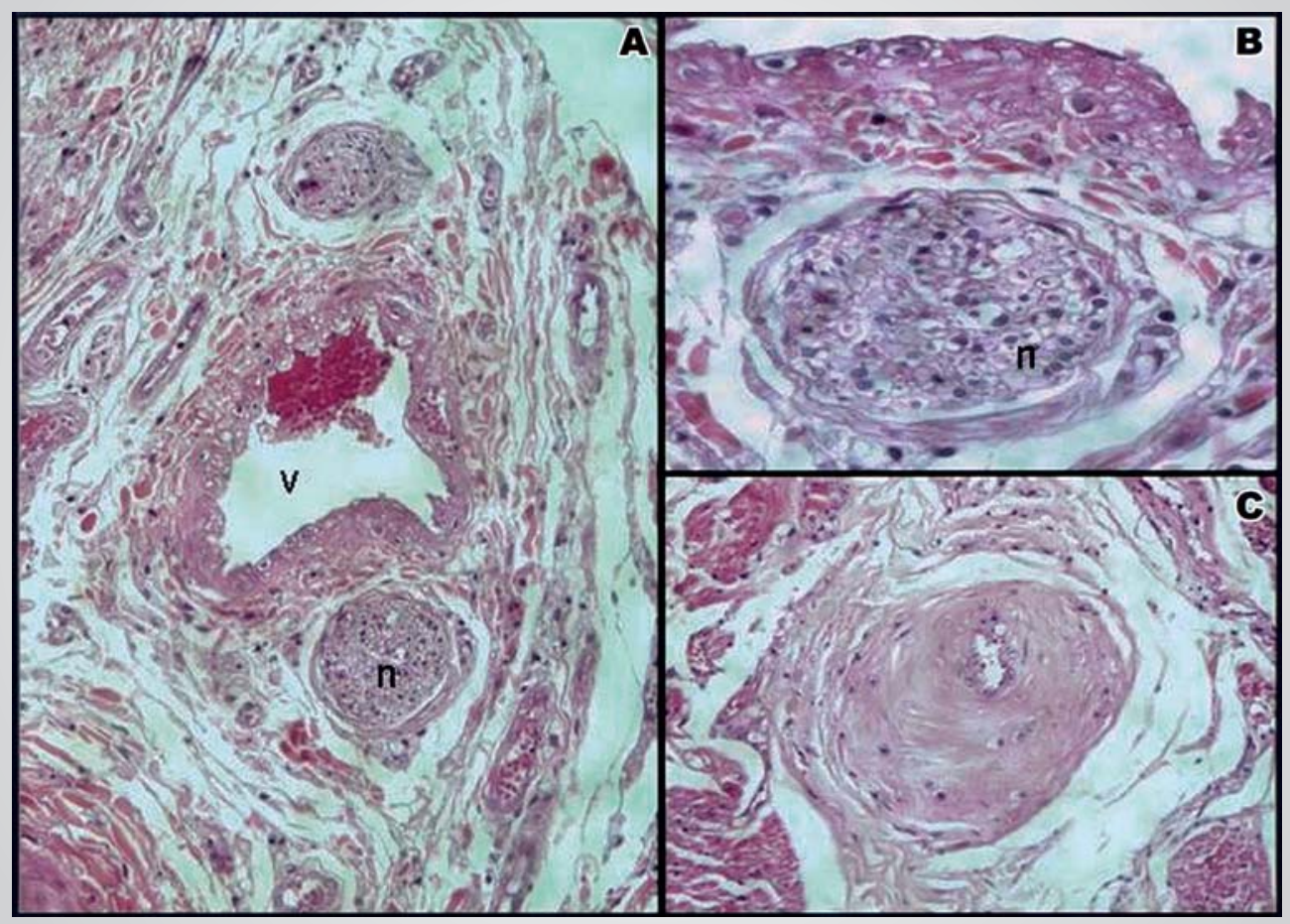

Fig 3 - Coração. A) ramo coronariano de pequeno calibre (v) e nervo (n); B) detalhe da figura anterior, mostrando células de aspecto vacuolado na parede arterial e na intimidade do nervo; C) pequena artéria intramiocárdica com algumas células claras, proliferação intimal e acentuada redução da luz. 


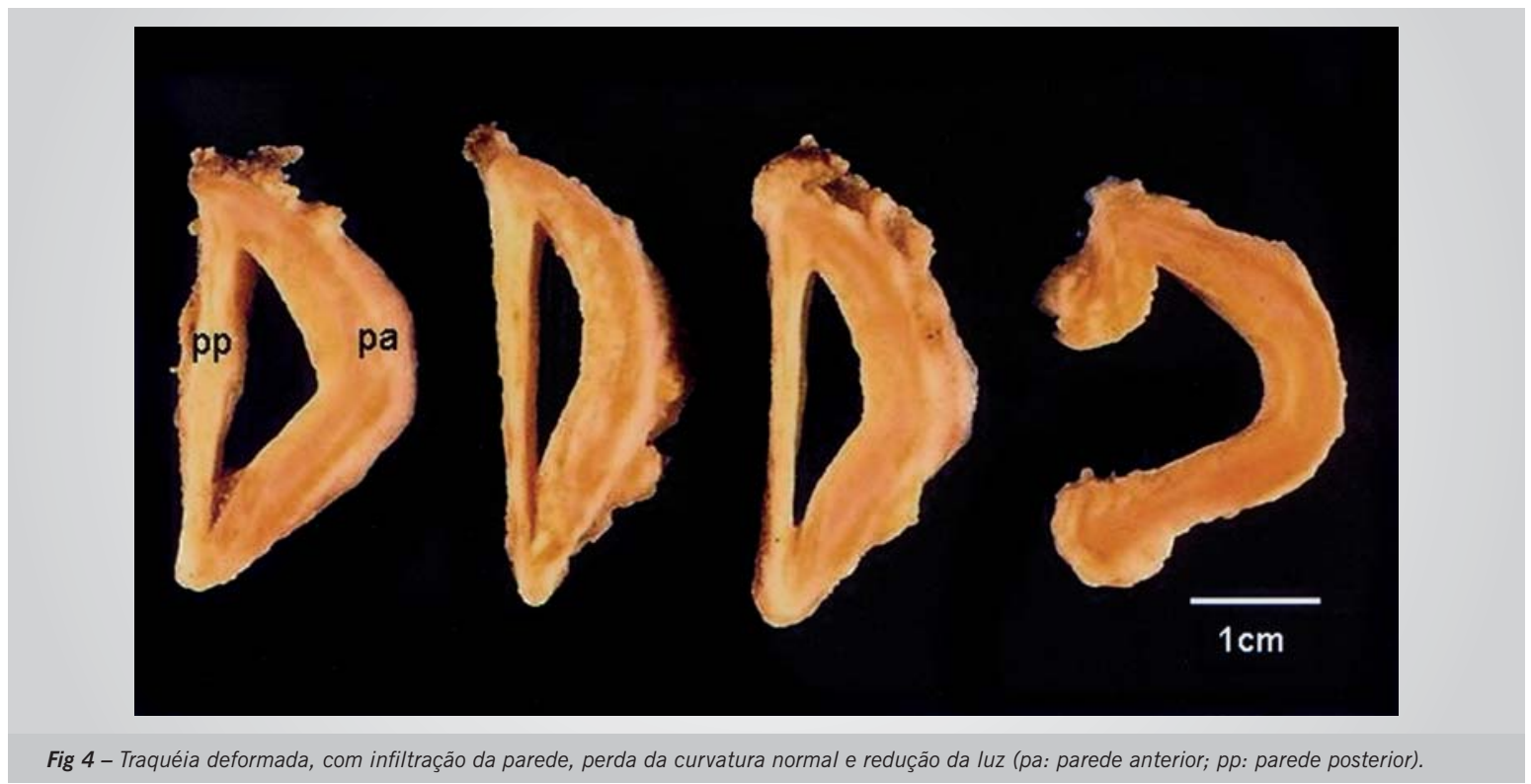

Fig 4 - Traquéia deformada, com infiltração da parede, perda da curvatura normal e redução da luz (pa: parede anterior; pp: parede posterior).

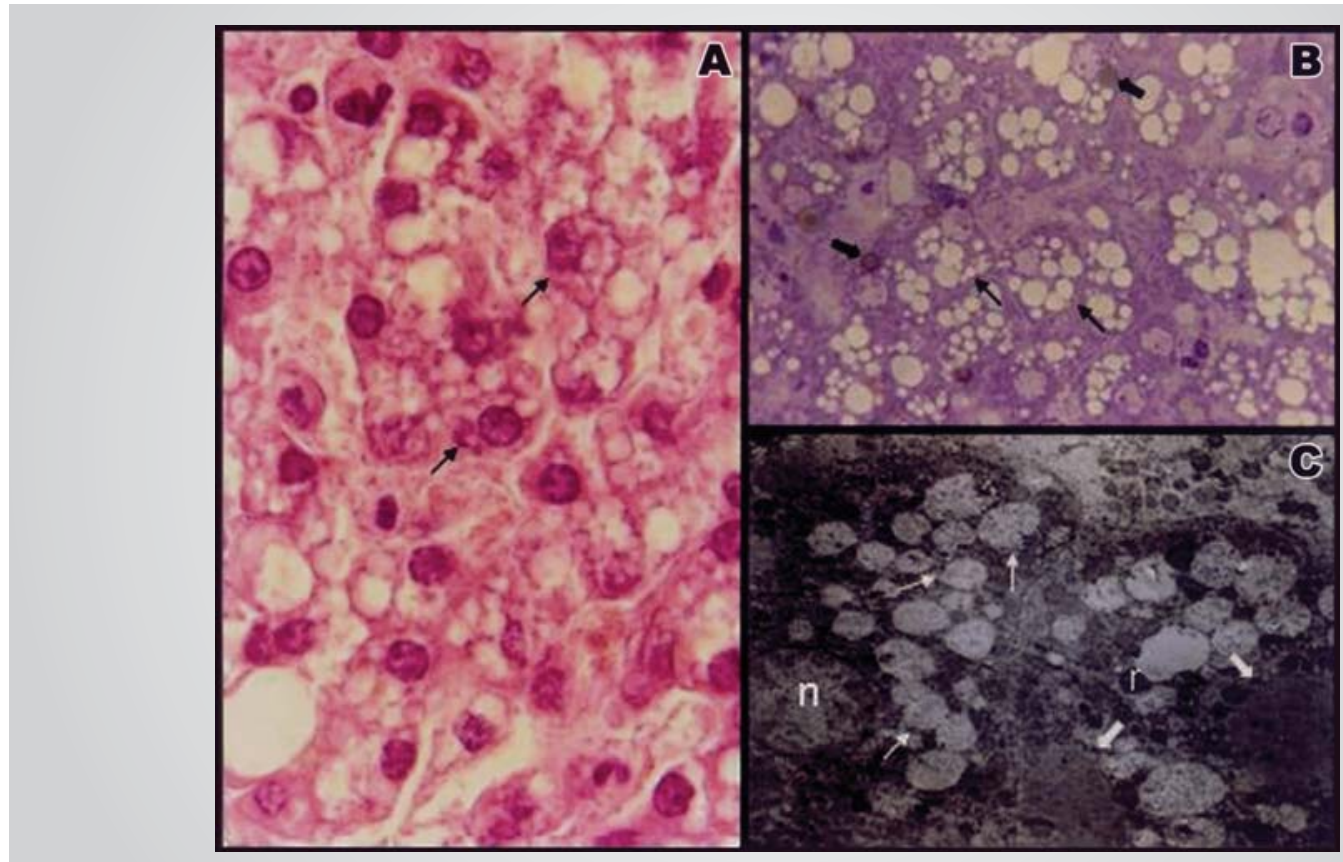

Fig 5 - Fígado. A) hepatócitos com citoplasma vacuolado (setas); hematoxilina-eosina. B) hepatócitos com citoplasma vacuolado (setas finas) e raras gotículas de lípides (setas grossas); corte semifino (tetróxido de ósmio / azul de toluidina). C) hepatócitos com vacúolos de conteúdo granular (setas finas), lípides (setas grossas), núcleo (n) e ribossomo (r); ultra-estrutura.

(hidrolases). Gerados pela clivagem dos proteoglicanos, os GAGs são polissacarídeos não-ramificados compostos por uma sucessão de dissacarídeos repetidos e alternados. Um dos monossacarídeos, em cada unidade, é representado por uma acetil-hexosamina e o outro pelo ácido glicurônico, pelo ácido idurônico ou pela galactose. Com exceção do ácido hialurônico (encontrado no líquido sinovial, no humor vítreo e no tecido conjuntivo frouxo), os demais GAGs são sulfatados e incluem o condroitin-sulfato (encontrado na cartilagem, nos ossos e na córnea), o heparan-sulfato (encontrado no pulmão, nas artérias, nos fibroblastos da pele, na lâmina basal e no glicocálice), o ceratan-sulfato (encontrado na córnea, nos discos intervertebrais e na cartilagem) e o dermatansulfato (de ampla distribuição no organismo, incluídos os vasos sangüíneos, o coração e, particularmente, as valvas cardíacas). Pelo fato de serem em sua maioria sulfatados e por possuírem numerosos filamentos carboxila, os GAGs são moléculas muito ácidas e com muitas cargas negativas, que atraem grande quantidade de íons sódio - e, portanto, de água - , o que confere turgência à matriz extracelular. Como a degradação dos GAGs depende da disponibilidade de diversas enzimas lisossômicas, a atividade deficiente de tais enzimas favorece seu acúmulo 
nos tecidos, com uma série de conseqüências (cognitivas, comportamentais e físicas, com destaque para variadas deformidades esqueléticas que, em conjunto, configuram a chamada dysostosis multiplex).

Reconhecem-se, basicamente, seis tipos de MPSs (tipos I, II, III, IV, VI e VII), aos quais se juntou, em 1996, um novo tipo (MPS IX), a partir do relato do caso de uma adolescente com deficiência de hialuronidase que exibia, ao exame clínico, múltiplas massas periarticulares, derivadas de partes moles ${ }^{3,4}$. A única forma de identificar, com certeza, os diferentes tipos, consiste na dosagem enzimática, realizada, tradicionalmente, nos leucócitos, em fibroblastos cultivados, no soro, no líquido amniótico e nos vilos coriônicos. Isso porque mais de um tipo exibe as mesmas características de eliminação urinária. Assim, por exemplo, demonstra-se pela eletroforese (ou pela cromatografia) a excreção de dermatan-sulfato e heparansulfato tanto no tipo I (em suas variantes: síndrome de Hurler, síndrome de Hurler-Scheie e síndrome de Scheie), quanto no tipo II (síndrome de Hunter) e no tipo VII (síndrome de Sly), decorrentes, respectivamente, da deficiência de alfa-L-iduronidase, iduronato-2-sulfatase e beta-glicuronidase. A partir da publicação pioneira de Chamoles e cols., datada de 2001 , surgiu a possibilidade de realizar a dosagem enzimática em papel-filtro, que se tem mostrado mais fácil, menos dispendiosa e mais rápida do que a dosagem a partir dos leucócitos ou de fibroblastos cultivados, além de facilitar o exame dos recém-nascidos, nos quais a retirada de maior quantidade de sangue pode não ser recomendável ou factível ${ }^{5}$.

Com exceção da MPS II, as demais são autossômicas recessivas, ou seja, quando os pais são portadores do gene defeituoso há um risco de $25 \%$, em cada gestação, de que o concepto seja acometido. A MPS II, por sua vez, é transmitida, a exemplo da hemofilia, por herança recessiva ligada ao cromossomo $\mathrm{X}$, acometendo, quase exclusivamente, pessoas do sexo masculino, embora haja relatos esporádicos de mulheres acometidas, em decorrência, por exemplo, da inativação unilateral do cromossomo X paterno não-mutante ${ }^{6}$.

Os pacientes, em sua maioria, atingem a adolescência e, alguns deles, a idade adulta; o óbito, quando sobrevém, deve-se, em geral, a complicações cardiorrespiratórias. Identificam-se graus variados de retardo mental e de dismorfismo somático, incluído o aspecto grosseiro da face, de modo a justificar o termo "gargoilismo", aplicado de forma genérica às MPSs e, particularmente, à síndrome de Hurler (de "gárgula", substantivo feminino definido pelo Dicionário Houaiss como "desaguadouro, parte saliente das calhas de telhados que se destina a escoar águas pluviais a certa distância da parede e que, especialmente na Idade Média, era ornada com figuras monstruosas, humanas ou animalescas" e pelo Novo Dicionário Aurélio como "final esculpido, quase sempre representando figuras grotescas, que escoa as águas das calhas para longe das paredes").
Conforme já foi mencionado, no caso de C.J.S. não foi possível avaliar a excreção urinária de GAGs, nem identificar a enzima lisossômica deficiente. No entanto, no segundo semestre de 2005 , surgiu a oportunidade de examinar o irmão sobrevivente (A.L.S.), acometido pela mesma afecção, que completara 30 anos no mês de abril. Num primeiro momento foram realizados, em sua urina, testes de triagem (brometo de cetiltrimetilamônio e azul de toluidina), que resultaram positivos, sugerindo a presença de GAGs, de modo a reforçar o diagnóstico clínico de MPS, embora, eventualmente, semelhante achado possa ser observado em outras condições, como, por exemplo, na síndrome de Marfan e na ônicoosteodisplasia hereditária (nail-patella syndrome). Num segundo momento detectou-se, pela eletroforese urinária, expressiva quantidade de dermatan-sulfato e heparansulfato, de modo a tornar improvável o diagnóstico de MPS III, MPS IV ou MPS VI, mas deixando em aberto as possibilidades de MPS I, MPS II e MPS VII (fig. 6). Além disso, identificou-se pequena quantidade de condroitinsulfato, achado destituído de significado patológico. Posteriormente, uma amostra de sangue colhida em papelfiltro foi encaminhada para o Serviço de Genética Médica do Hospital de Clínicas de Porto Alegre (Laboratório de Erros Inatos do Metabolismo). Foram avaliadas as enzimas alfa-L-iduronidase (deficiente na MPS I), arilsulfatase $B$ (deficiente na MPS VI), beta-glicuronidase (deficiente na MPS VII) e iduronato-2-sulfatase (deficiente na MPS II). Para a alfa-L-iduronidase obteve-se o valor de 3,5 $\mu$ moles/h/L (valores de referência, VR, entre 1,13 e $5,50 \mu$ moles/h/L), para a arilsulfatase B o valor de 6,1 $\mu \mathrm{moles} / \mathrm{h} / \mathrm{L}$ (VR entre 5,3 e 22,0 $\mu$ moles/h/L) e para a beta-glicuronidase o valor de 26,0 $\mu$ moles/h/L (VR entre 4,02 e $14,79 \mu$ moles/h/L), ao passo que a atividade da enzima iduronato-2-sulfatase foi indetectável (VR entre 12,43 e 22,70 $\mu$ moles/h/L). Tais resultados apontam para o diagnóstico de MPS II, embora seja forçoso reconhecer que o diagnóstico definitivo dependeria, em razão da experiência acumulada, da aplicação da metodologia clássica, ou seja, do ensaio enzimático a partir dos leucócitos, de fibroblastos cultivados ou do soro.

Tendo em vista o resultado da avaliação laboratorial de A.L.S., que, seguramente, pode ser extrapolado para o caso dos irmãos C.J.S. (razão de ser desta publicação) e C.A.S. (que faleceu durante o sono), merece registro o diagnóstico genérico de glicogenose firmado neste último com base em punção-biopsia hepática realizada em 1976. Trata-se de diagnóstico certamente equivocado, sendo lícito atribuir tal equívoco - a despeito de não terem sido localizadas as preparações histológicas - à não valorização do contexto clínico global e à inadequada interpretação dos achados morfológicos. Com efeito, o aspecto vacuolado dos hepatócitos, secundário ao acúmulo de GAGs, pode ter sido indevidamente interpretado como resultante de hipotética remoção do glicogênio após fixação em formol dos fragmentos de fígado obtidos pela punção-biopsia. Quando se trata efetivamente de 
glicogenose, as células tumefeitas e vacuoladas (células claras, com o aspecto de células vegetais), coram-se pelo PAS, mas deixam de fazê-lo se o material é previamente tratado com diastase. Ao contrário, no caso das MPSs as células, carregadas de GAGs, também são PAS positivas, mas resistem à digestão pela diastase. Ademais, o aspecto do glicogênio à microscopia eletrônica é bastante peculiar. Vale ainda assinalar que, em algumas glicogenoses - em especial no tipo II (doença de Pompe), decorrente da deficiência de alfa-1,4-glucosidase lisossômica -, pode haver expressivo acometimento cardíaco, sobretudo em crianças, pois a afecção costuma ser fatal antes da idade de dois anos. Não obstante, há relatos esporádicos de casos em adultos, como aquele de um homem de 45 anos, cujo diagnóstico foi firmado mediante biopsia endomiocárdica do ventrículo direito ${ }^{7}$.

As características do acometimento cardíaco nas MPSs, mais freqüente nos tipos I e II, coincidem, em sua maior parte, com as observadas, à necropsia, no caso ora relatado, e incluem alterações miocárdicas, valvares, coronarianas e do endocárdio parietal. Chama a atenção - em consonância com os dados da literatura - a ausência de fenômenos trombóticos (trombose parietal ou coronariana), fato atribuído, entre outras possíveis causas, ao acúmulo, no endocárdio parietal e na íntima vascular, de heparan-sulfato e dermatan-sulfato, compostos dotados de propriedades anticoagulantes ${ }^{8}$. A propósito, em casos de trombocitopenia induzida pela heparina, tem sido proposta sua substituição pelo danaparóide sódico, cujo princípio ativo, extraído da mucosa intestinal do porco, consiste numa mistura de heparan-sulfato (84\%), dermatan-sulfato $(12 \%)$ e condroitin-sulfato $(4 \%)^{9}$. No que concerne ao aumento da espessura da parede do VE, observado à ecocardiografia - e confirmado à necropsia - , pode-se atribuí-lo, sobretudo, à infiltração miocárdica, fato observado não apenas nas MPSs, como também em outras doenças de depósito, a ponto de se utilizar o termo pseudo-hipertrofia para caracterizá-lo. Não obstante, pode coexistir hipertrofia verdadeira, secundária à sobrecarga hemodinâmica imposta pelas disfunções valvares. Nos casos de MPS que evoluem com insuficiência cardíaca, esta parece dever-se à associação de vários fatores, como a própria sobrecarga hemodinâmica, o acúmulo de GAGs, o estímulo à colagenogênese, a insuficiência coronariana e a hipóxia.

No que diz respeito ao coração, o aspecto insólito do caso ora relatado consiste na presença de pequena dilatação sacular (aneurisma) apical constituída pela herniação do endocárdio entre as fibras musculares do VE. Trata-se de lesão muito semelhante à chamada lesão vorticilar, quando acompanhada do afastamento das fibras musculares que constituem o vórtex do VE, por muitos considerada patognomônica da cardiopatia chagásica crônica (CChCr). De patogênese controversa, mas provavelmente multifatorial - ficando as divergências por conta do peso conferido aos diversos fatores e da seqüência dos acontecimentos até o seu pleno desenvolvimento -, a lesão vorticilar na CChCr ocorre tanto em corações de peso normal quanto em presença de expressiva cardiomegalia. Apresenta-se, morfologicamente, sob duas formas distintas que, possivelmente, dependem de mecanismos patogenéticos diversos. Uma forma, menos comum, consiste num simples adelgaçamento da parede ventricular, que se associa, nos casos mais avançados, à dilatação e, às vezes, ao abaulamento da região vorticilar, sem que haja uma delimitação precisa entre a parede do vórtex e o resto da parede ventricular. No entanto, a forma mais freqüente é, justamente, a lesão com afastamento dos feixes musculares que constituem o vórtex, ou seja, dos músculos bulbo-espiral superficial e sino-espiral

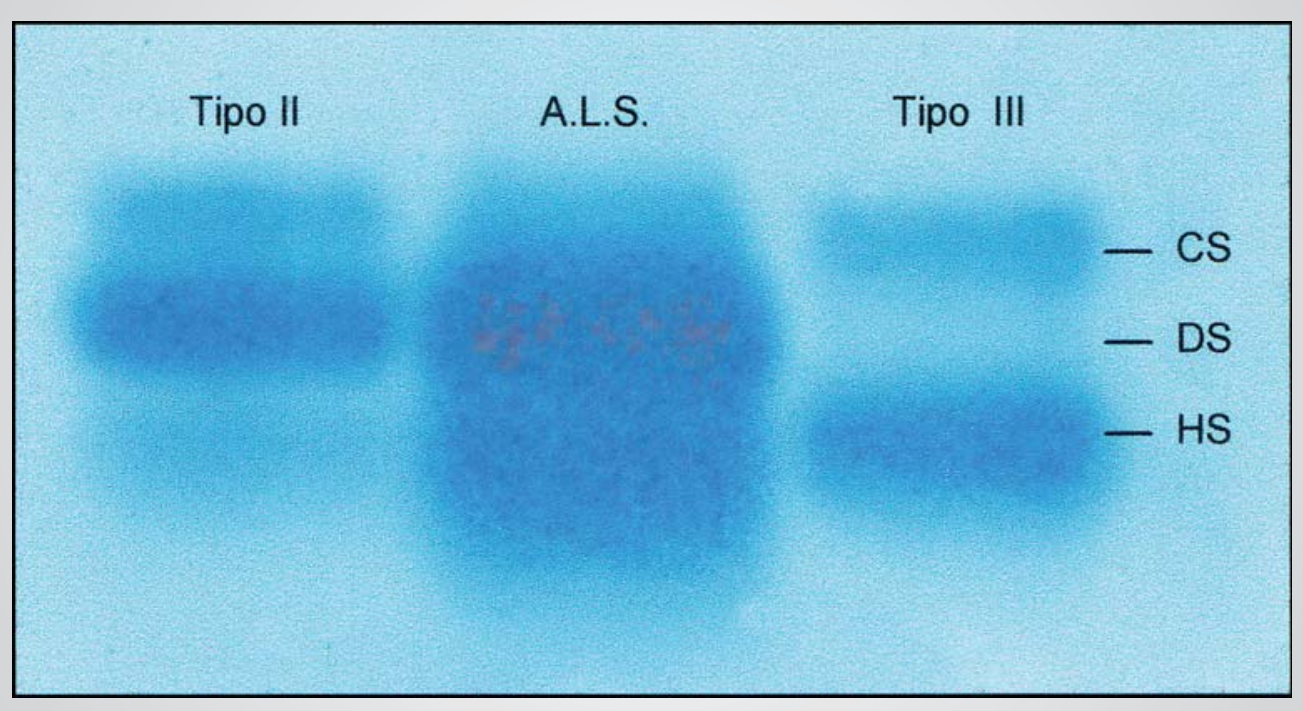

Fig 6 - Eletroforese de GAGs na urina de A.L.S., demonstrando eliminação de heparan-sulfato (HS) e dermatan-sulfato (DS), além de condroitin-sulfato (CS). Para comparação, eletroforese de casos confirmados de MPS II (com o mesmo perfil de eliminação urinária de A.L.S.) e de MPS III ( eliminação de HS e CS, mas não de DS). 
superficial, com a insinuação do endocárdio entre eles, à maneira de hérnia ou de dedo de luva.

Ressalvadas as diferenças entre as duas afecções (CChCr e MPS), dado o caráter inflamatório da primeira, mas não da segunda, parece lícito supor, com base nos achados anatomopatológicos, que existam pontos de contato entre elas, ao se especular sobre a patogênese da lesão apical no caso ora relatado. Partindo dessa premissa, pode-se invocar, para explicar seu surgimento, a participação de fatores como a infiltração endomiocárdica e os fenômenos regressivos das fibrocélulas, particularmente evidentes nas imediações da formação aneurismática; a expansão do conjuntivo intra e extrafascicular, com desorganização e afastamento dos feixes musculares; as lesões do sistema nervoso autônomo (acometimento dos gânglios e nervos cardíacos); as conspícuas lesões vasculares (bem mais evidentes que as observadas na CChCr); o possível acometimento do sistema de condução (bem documentado nas MPSs) e, finalmente, a participação do chamado "fator mecânico", invocado por alguns autores a propósito da $\mathrm{CChCr}^{10}$. A ação conjunta de tais fatores seria favorecida pela peculiar constituição anatômica do vórtex esquerdo.

Ao que tudo indica há apenas dois registros na literatura de aneurismas apicais associados às MPSs, ambos em pacientes com síndrome de Hunter, a exemplo do caso ora relatado.

Em 1982, Oliver e cols. ${ }^{11}$ descreveram o caso de um paciente de 32 anos com uma cardiopatia complexa caracterizada pela associação de insuficiência mitral, estenose aórtica e dilatação aneurismática do ápex do $V E$, que se comportava como zona discinética à ventriculografia, na ausência de lesões obstrutivas à coronariografia. 0 paciente foi submetido a tratamento cirúrgico, que consistiu na ressecção do aneurisma apical, substituição da valva mitral e colocação de um tubo valvado comunicando a ponta do VE com a aorta abdominal, mas faleceu no pós-operatório imediato em síndrome de baixo débito. 0 exame histopatológico de um fragmento da zona aneurismática revelou substituição quase completa das fibras miocárdicas por colágeno e abundantes células claras. Vinte anos depois, Kettles e cols. ${ }^{12}$ descreveram o caso de um homem reconhecidamente cardiopata desde a infância que, aos 27 anos, apresentou evidente deterioração clínica, falecendo pouco tempo depois da detecção, pela ressonância magnética, de aneurisma apical do VE, de paredes finas. À necropsia havia acometimento das valvas mitral e aórtica, espessamento difuso, circunferencial, das coronárias, mas sem estenose significativa, e presença de aneurisma apical de seis centímetros, cuja parede era composta de tecido fibroso denso, não havendo menção ao acúmulo de células claras observado no caso de Oliver e cols.

Deve ser enfatizado que nos casos descritos por Oliver e cols. (1982) e Kettles e cols. (2002) a formação aneurismática da ponta do VE certamente contribuiu para a deterioração hemodinâmica dos pacientes. 0 mesmo não se pode dizer da lesão análoga observada no caso ora relatado, a qual, por suas exíguas dimensões, parece destituída da mesma importância, do ponto de vista de sua repercussão funcional. Aliás, o óbito do paciente deveuse, ao que tudo indica, a causa não-cardíaca, ou seja, à insuficiência respiratória decorrente da obstrução das vias aéreas associada ao processo broncopneumônico.

Até um passado recente, o tratamento das MPSs baseava-se em medidas de suporte, que variavam desde a assistência fisioterápica e psicossocial, até a pressão positiva contínua nas vias aéreas (para tratamento da apnéia do sono), a traqueostomia (para contornar a obstrução das vias aéreas superiores) ou a substituição de valvas cardíacas. De algum tempo para cá têm sido preconizadas outras modalidades terapêuticas, na expectativa de retardar a progressão das manifestações clínicas ou, até mesmo, de promover, pelo menos parcialmente, sua regressão. Merecem registro o transplante de medula óssea, capaz de beneficiar pacientes com MPS I-H (síndrome de Hurler) ou MPS VI, desde que realizado em tenra idade ${ }^{13}$, e, mais recentemente, a terapia de reposição enzimática. Assim, por exemplo, a enzima artificial laronidase, obtida por engenharia genética e testada, inicialmente, em camundongos, foi aprovada, em abril de 2003, na Europa e nos EUA, para o tratamento da MPS I em seres humanos. A reposição de laronidase parece diminuir a excreção urinária de GAGs, reduzir a hepatomegalia, melhorar a função pulmonar, melhorar a amplitude dos movimentos articulares, atenuar a apnéia do sono e melhorar o desempenho dos pacientes no teste de caminhada de seis minutos. Não se esperam benefícios para as alterações do sistema nervoso central pela dificuldade imposta pela barreira hematoencefálica, não obstante haja indícios preliminares de que, pelo menos no modelo canino, essa limitação possa ser até certo ponto contornada pela injeção intratecal da enzima ${ }^{14}$. No que concerne ao acometimento cardíaco não foram, até o momento, observados resultados inequívocos com essa modalidade terapêutica, havendo apenas referências isoladas à melhora de algumas manifestações clínicas dele decorrentes. Deve ainda ser ressaltado que em cerca de $90 \%$ dos casos identifica-se a formação de anticorpos contra a laronidase, não se sabendo com certeza qual o impacto de tal ocorrência sobre os resultados do tratamento a longo prazo. No que diz respeito à MPS II, foram divulgados, em meados de 2005, os resultados encorajadores do estudo AIM (Assessment of I2S in MPS II), ensaio clínico randomizado, duplo-cego, controlado com placebo, destinado a avaliar a segurança e a eficácia da reposição, por via intravenosa, da enzima idursulfase, também obtida por engenharia genética, em pacientes de alguns países, incluído o Brasil (Serviço de Genética Médica do Hospital de Clínicas de Porto Alegre, coordenado pelo Prof. Roberto Giugliani). A liberação 
do produto pelos órgãos reguladores poderá beneficiar, de acordo com algumas estimativas, cerca de 2.000 pacientes em todo o mundo.

A despeito da esperança depositada na terapia de reposição enzimática, a forma mais radical de abordagem das MPSs seria mediante a terapia gênica (transferência de material genético, com a inserção de genes funcionais nas células alvo, portadoras de genes defeituosos), em que pesem os inúmeros obstáculos a serem transpostos para o real sucesso do procedimento, atualmente restrito a animais de experimentação. À guisa de ilustração, merece registro a demonstração do efeito benéfico de tal modalidade terapêutica sobre o acometimento cardíaco de cães com MPS VII. Os animais receberam, no período neonatal, por via intravenosa, um vetor retroviral (retrovírus modificado, incapaz de replicar) inoculado com a seqüência do gene que comanda a produção da enzima deficiente (no caso a beta-glicuronidase). A avaliação dos cães tratados e do grupo controle baseou-se no exame clínico, no ecodopplercardiograma e nos achados de necropsia (macroscopia, histopatologia e histoquímica) ${ }^{15}$.

( Dr. Luiz Otávio Savassi Rocha, Dra. Eugênia Ribeiro Valadares)

\section{Agradecimentos}

Aos Srs. Ana Maria Salvador Pereira, Bruno de Souza Teixeira, Élcia Geralda Dias, Guilherme Lages Savassi Rocha, Leonardo Maurício Diniz e Rosália Morais Torres, pela inestimável colaboração.

\section{REFERÊNCIAS}

1. Triage BNP Test Product Insert. San Diego CA: Biosite Diagnostics Inc. 2000.

2. Morrison LK, Harrison A, Krishnaswamy P, Kazanegra R, Clopton P, Maisel A. Utility of a rapid B-natriuretic peptide assay in differentiating congestive heart failure from lung disease in patients presenting with dyspnea. J Am Coll Cardiol. 2002; 39: 202-9.

3. Natowicz MR, Short MP, Wang Y, et al. Clinical and biochemical manifestations of hyaluronidase deficiency. N Engl J Med. 1996; 335: 1029-33.

4. Triggs-Raine B, Salo TJ, Zhang H, Wicklow BA, Natowicz MR. Mutations in HYAL 1, a member of a tandemly distributed multigene family encoding disparate hyaluronidase activities, cause a newly described lysosomal disorder, mucopolysaccharidosis IX. Proc Natl Acad Sci USA. 1999; 96: 6296-300.

5. Chamoles NA, Blanco M, Gaggioli D. Diagnosis of $\alpha$-L-iduronidase deficiency in dried blood spots on filter paper: the possibility of newborn diagnosis. Clin Chem. 2001; 47: 780-1.

6. Tuschl K, Gal A, Paschke E, Kircher S, Bodamer OA. Mucopolysaccharidosis type II in females: case report and review of literature. Pediatr Neurol. 2005; 32: 270-2.

7. Ben-Ami R, Puglisi J, Haider T, Mehta D. The Mount Sinai Hospital clinicopathological conference: a 45-year-old man with Pompe's disease and dilated cardiomyopathy. The Mount Sinai J Med. 2001; 68:205-12

8. Rentería VG, Ferrans VJ, Roberts WC. The heart in the Hurler syndrome. Gross, histologic and ultrastructural observations in five necropsy cases. Am J Cardiol. 1976; 38: 487-501.

9. Warkentin TE, Greinacher A. Heparin-induced thrombocytopenia: recognition, treatment, and prevention: the Seventh ACCP Conference on Antithrombotic and Thrombolytic Therapy. Chest. 2004; 126 : 311S-337S.

10. Raso P, Chapadeiro E, Tafuri WL, Lopes ER, Rocha A. Anatomia patológica da cardiopatia crônica. In: Cançado JR, Chuster M (eds.). Cardiopatia Chagásica. Belo Horizonte: Fundação Carlos Chagas, 1985.

11. Oliver J, Garcia Fernandez F, Sotillo J, et al. Insuficiencia mitral y estenosis aórtica severa en un paciente con síndrome de Hunter. Rev Esp Cardiol. 1982; 35: 465-9.

12. Kettles DI, Sheppard M, Liebmann RD, Davidson C. Left ventricular aneurysm, aortic valve disease and coronary narrowing in a patient with Hunter's syndrome. Cardiovasc Pathol. 2002; 11: 94-6.

13. Peters C, Steward CG. Hematopoietic cell transplantation for inherited metabolic diseases: an overview of outcomes and practice guidelines. Bone Marrow Transplant. 2003; 31: 229-39.

14. Kakkis E, Mc Entee M, Vogler C, et al. Intrathecal enzyme replacement therapy reduces lysosomal storage in the brain and meninges of the canine model of MPS I. Mol Genet Metab. 2004; 83: 163-74.

15. Sleeper MM, Fornasari B, Ellinwood NM, et al. Gene therapy ameliorates cardiovascular disease in dogs with mucopolysaccharidosis VII. Circulation. 2004; 110: 815-20. 